\title{
The effects of adding agrimony and sage extracts to water on blood biochemistry and meat quality of broiler chickens
}

\author{
Peter Supuka ${ }^{1}$, Slavomír Marcinčák ${ }^{2}$, Peter Popelka², Vladimír Petrovič ${ }^{3}$, \\ Ladislav Molnár ${ }^{4}$, Iveta Maskal'ová ${ }^{1}$, Pavol Kovalík², Dana Marcinčáková5, \\ Anna Supuková6, Peter Turek ${ }^{2}$
}

\begin{abstract}
${ }^{1}$ University of Veterinary Medicine and Pharmacy in Košice, Institute of Nutrition, Dietetics and Feed Production, ${ }^{2}$ Department of Food Hygiene and Technology, ${ }^{3}$ Department of Enviroment, Veterinary Legislation and Economy, ${ }^{4} \mathrm{Clinic}$ for Birds and Exotic Animals, ${ }^{5}$ Department of Drug and Pharmaceutical Technology, Košice, Slovak Republic

${ }^{6}$ Pavol Jozef Šafárik University, Faculty of Medicine, Department of Medical and Clinical Biochemistry, Košice, Slovak Republic
\end{abstract}

Received January 8, 2014

Accepted January 14, 2015

\begin{abstract}
The aim of our study was to determine the effects of supplementation of agrimony extract (Agrimonia eupatoria L.) and a combination of agrimony with sage extract (Salvia officinalis L.) to water during the fattening period of broiler chickens on selected biochemical and antioxidant indicators in blood, and on the nutritional composition and oxidative stability of meat. A total of 117 Cobb 500 chicks were randomly divided on the day of hatching into three groups $(n=39$ in each) and fattened for 42 days. All groups were fed the same diets. In experimental group A water was supplemented with agrimony extract $(0.2 \%)$. In experimental group AS water was supplemented with a combination of agrimony $(0.1 \%)$ and sage $(0.1 \%)$ extracts. Group $\mathrm{C}$ was control without supplementation. The total cholesterol, low density lipoproteins and malondialdehyde in serum were decreased $(P<0.05)$, dry matter and fat content in meat were increased $(P<0.05)$ in group A. The activity of superoxide dismutase in blood and the amount of thiobarbituric acid reactive substances in thigh meat on days 1 and 8 of storage under chilling conditions were lower $(P<0.05)$ in both experimental groups compared to control. Our results indicate that supplementation of agrimony and sage extract to water can beneficially influence the antioxidant status as well as oxidative stability of thigh meat and thus improve meat quality. This is a first similar study comparing addition of plant extracts to water in broiler nutrition.
\end{abstract}

Antioxidant status, lipid oxidation, herbal extracts, poultry

Current legislation of the European Union brings new insights into animal fattening programmes as a result of increased attention for the quality of food of animal origin. Therefore, animal nutrition experts try to find ways to produce naturally products of animal origin with preferable quality (Vašková et al. 2011). Increasing interest is devoted to using plant extracts (e.g. essential oils, oleoresins, and flavonoids) in animal and poultry nutrition required for the food industry, because herbal substances possess a much higher biological activity compared to plants from which they were derived (Windisch et al. 2008; Gräber et. al. 2014). Promising results have been obtained by research in this field so far, when supplementation of some herbal substances had a positive impact not only on the growth performance of broiler chickens, but also on their antioxidant status as well as on the oxidative stability of meat. For these reasons, use of natural "herbal" antioxidants in the fattening of broilers is considered to be a suitable method to achieve better antioxidant status of poultry, and also higher oxidation stability of poultry meat during storage (Luna et al. 2010; Jayasena and Jo 2014). Agrimony (Agrimonia eupatoria L.) and sage (Salvia officinalis L.) are among the most frequently studied herbs due to their high content of active substances with antioxidant properties (Giao et al. 2009; Ryzner et al. 2013).

Address for correspondence:

doc. MVDr. Slavomír Marcinčák, PhD.

Department of Food Hygiene and Technology

University of Veterinary Medicine and Pharmacy in Košice

Komenského 73, 04181 Košice, Slovak Republic

Phone: +421915984756

E-mail: slavomir.marcincak@uvlf.sk

http://actavet.vfu.cz/ 
Effects of the addition of $0.2 \%$ agrimony extract and a combination of $0.1 \%$ agrimony extract with $0.1 \%$ sage extract to water on selected biochemical and antioxidant indicators, and on the chemical composition and oxidative stability of broiler meat during storage $\left(4{ }^{\circ} \mathrm{C}, 8\right.$ days $)$ were investigated.

\section{Materials and Methods}

The study was carried out using a total of $117 \mathrm{Cobb} 500$ broiler chickens. One-day-old chicks were randomly divided into 3 groups of 39 birds. Each group had three replicates (13 birds per pen). In all groups, broiler chickens were fed with the same basal diets for 42 days (Table 1). The "Starter" broiler feed was fed from day 1 to day 14, the "Grower" broiler feed from day 15 to day 35, and the "Finisher" broiler feed from day 36 to day 42. No additives were added to the water in the control group (C) but the broiler chickens in the $1^{\text {st }}$ and $2^{\text {nd }}$ experimental groups received the water supplemented with $0.2 \%$ agrimony extract and the combination of $0.1 \%$, agrimony extract and $0.1 \%$ sage extracts (A and AS, respectively). Powdered preparations of both extracts were purchased from Calendula (Nova Lubovna, Slovak Republic). Fresh water extracts were prepared and changed each morning and afternoon. During the entire fattening period the broiler chickens had free access to water and feed. Temperature and lighting regimes were in accordance with standards for the care of fattening broiler chickens (COBB Broiler Management Guide). The experimental protocol was approved by the Ethics Committee of the University of Veterinary Medicine and Pharmacy in Košice and the State Food and Veterinary Administration of the Slovak Republic (Ro. 1941/07-221).

On day 42 of the fattening period, the broiler chickens were slaughtered by cervical dislocation and processed. Blood samples $(n=20)$ were collected into heparinized test tubes and centrifuged at $1180 \times g$ for 15 min to

Table 1. Composition of basal diets fed to broiler chickens.

\begin{tabular}{lccc}
\hline Ingredients & $\begin{array}{c}\text { Starter diet } \\
\text { (Days 1 to 14) }\end{array}$ & $\begin{array}{c}\text { Grower diet } \\
(15 \text { to 35) }\end{array}$ & $\begin{array}{c}\text { Finisher diet } \\
(36 \text { to } 42)\end{array}$ \\
\hline Wheat (\%) & 35.0 & 35.0 & 38.0 \\
Corn (\%) & 31.0 & 23.1 & 22.1 \\
Soybean meal (\%) & 24.5 & 19.1 & 16.5 \\
Sunflower oilcakes (\%) & 5.00 & 7.0 & 7.0 \\
Sunflower oil (\%) & - & 1.7 & 2.3 \\
Limestone (\%) & 1.41 & 1.45 & 1.54 \\
Monocalcium phosphate (\%) & 1.23 & 1.0 & 0.90 \\
Natrium chloride (\%) & 0.25 & 0.25 & 0.25 \\
Vitamin-mineral premix (\%) & 0.50 & 0.50 & 0.50 \\
Nutrient composition & & 13.0 & 13.0 \\
Moisture (\%) & 12.0 & 12.6 & 12.6 \\
Metabolizable energy (MJ/kg) & 12.3 & 19.0 & 18.0 \\
Crude protein (\%) & 20.0 & 5.0 & 5.0 \\
Fibre (\%) & 4.0 & 7.0 & 7.0 \\
Ash (\%) & 7.0 & 4.0 & 4.0 \\
Total fat (\%) & 4.0 & 1.12 & 1.15 \\
Lysine (\%) & 1.21 & 0.48 & 0.45 \\
Methionine (\%) & 0.51 & 0.82 & 0.80 \\
Met + Cys (\%) & 0.86 & 0.85 & 0.85 \\
Calcium (\%) & 0.90 & 0.33 \\
Total phosphorus (\%) & 0.45 & & \\
\hline
\end{tabular}

${ }^{a}$ The vitamin-mineral premix provided per $\mathrm{kg}$ of diet: vitamin A $12000 \mathrm{IU}$, vitamin D3 $4000 \mathrm{IU}$, vitamin $\mathrm{K}$ $4 \mathrm{mg}$, vitamin E $100 \mathrm{mg}$, thiamine $3 \mathrm{mg}$, riboflavin $9 \mathrm{mg}$, niacin $60 \mathrm{mg}$, pantothenic acid $15 \mathrm{mg}$, pyridoxine $6.0 \mathrm{mg}$, cyanocobalamin $0.04 \mathrm{mg}$, biotin $0.2 \mathrm{mg}$, folic acid $2 \mathrm{mg}$, lysine $9.5 \mathrm{~g}$, methionine $4.0 \mathrm{~g}$, Se $0.1 \mathrm{mg}$, Zn 100 mg, I 1 mg, Co 0.4 mg, Mn 110 mg, Cu 15 mg, Fe 120 mg 
separate plasma or settled at room temperature for $30 \mathrm{~min}$ to obtain blood serum. Whole blood, serum, and plasma samples for the analyses of antioxidant indices were frozen and stored at $-65^{\circ} \mathrm{C}$ till analysed. The activity of blood glutathione peroxidase (GPx, EC 1.11.1.9) was determined by the method of Paglia and Valentine (1967) with a RANSEL kit (Randox, UK). The superoxide dismutase (SOD, EC 1.15.1.1) activity in erythrocytes was analysed by the method of Arthur and Boyne (1985) using the kit RANSOD (Randox, UK). E1lman's method (1958) was used to determine the concentration of sulphydryl groups in the plasma. The concentration of malondialdehyde (MDA) in plasma was measured with the modified fluorimetric method according to Jo and Ahn (1998).

High density lipoproteins (HDL) were measured in blood plasma. Low density lipoproteins (LDL), total cholesterol and triglycerides were determined in blood serum. All these indices were analysed immediately after processing by spectrophotometrical method using the biochemical analyser Cobas C111 (Roche Diagnostics Ltd., Switzerland).

Samples of breast and thigh muscles $(n=30)$ were obtained for analysis of the nutritional composition and oxidative stability in broiler meat. Dry matter content was determined by drying the meat samples at $105^{\circ} \mathrm{C}$ for $16 \mathrm{~h}$. The crude protein content was assessed using a Kjeltec Auto 1030 (Tecator Co., Sweden). The fat content was extracted in petroleum ether with Soxhlet apparatus and determined gravimetrically. The amount of thiobarbituric acid reactive substances (TBARS) as an indicator of the deterioration of lipids was performed according to Marcinčák et al. (2006) and measured spectrophotometrically at $532 \mathrm{~nm}$ (Helios $\gamma$, v. 4.6, Thermo spectronic, UK). Samples of thigh muscles were vacuum packed into polyethylene bags and stored in a refrigerator pre-set at the temperature of $4{ }^{\circ} \mathrm{C}$ for 8 days.

All data were analysed statistically using GraphPad Prism Software, Version 4.00 (Graphpad Prism, 2003). One-way analysis of variance (ANOVA) with post hoc Tukey's multiple comparison test was used to evaluate significance of differences between the control and experimental groups. Results are expressed as mean $\pm \mathrm{SD}$ and $P<0.05$ was considered as a significant difference.

\section{Results}

The effects of administration of $0.2 \%$ agrimony extract and a combination of $0.1 \%$ agrimony extract and $0.1 \%$ sage extract to water on the antioxidant and lipid status in the blood at the end of the fattening period are given in Table 2. In group A, decreased total cholesterol and LDL-cholesterol, SOD activity, and MDA concentration were determined compared to group C. A decrease in the SOD activity $(P<0.05)$, and a tendency to decrease $(P \leq 0.1309)$ in the MDA concentration were observed in group AS. In addition, concentrations of HDL-cholesterol, triglycerides, and MDA, and the GSHPx activity remained unchanged due to the supplementation in both experimental groups compared to the control group.

Table 2. Antioxidant and lipid status, and concentration of malondialdehyde in the blood after administration of extracts to water for 42 days of fattening of broiler chickens.

\begin{tabular}{lccc}
\hline Indices & C & A & AS \\
\hline SH groups $\left(\mathrm{mmol} \cdot l^{-1}\right)$ & $0.19 \pm 0.02$ & $0.21 \pm 0.03$ & $0.20 \pm 0.04$ \\
GPx in blood $\left(\mu \mathrm{kat} \cdot \mathrm{g}^{-1}\right.$ of $\left.\mathrm{Hb}\right)$ & $92.1 \pm 12.1$ & $107.6 \pm 18.7$ & $95.1 \pm 18.1$ \\
SOD in blood $\left(\mu \mathrm{kat} \cdot \mathrm{g}^{-1}\right.$ of Hb) & $2619 \pm 264^{\mathrm{a}}$ & $2199 \pm 327^{\mathrm{b}}$ & $1926 \pm 201^{\mathrm{b}}$ \\
MDA $\left(\mu \mathrm{mol} \cdot \mathrm{l}^{-1}\right)$ & $1.13 \pm 0.05^{\mathrm{a}}$ & $0.85 \pm 0.06^{\mathrm{b}}$ & $0.96 \pm 0.07^{\mathrm{a}}$ \\
Total cholesterol $\left(\mathrm{mmol} \cdot \mathrm{l}^{-1}\right)$ & $3.33 \pm 0.35^{\mathrm{a}}$ & $2.88 \pm 0.26^{\mathrm{b}}$ & $3.11 \pm 0.29^{\mathrm{a}, \mathrm{b}}$ \\
HDL-cholesterol $\left(\mathrm{mmol} \cdot \mathrm{l}^{-1}\right)$ & $2.42 \pm 0.35$ & $2.43 \pm 0.22$ & $2.40 \pm 0.35$ \\
LDL-cholesterol $\left(\mathrm{mmol} \cdot \mathrm{l}^{-1}\right)$ & $0.64 \pm 0.16^{\mathrm{a}}$ & $0.45 \pm 0.11^{\mathrm{b}}$ & $0.61 \pm 0.08^{\mathrm{a}}$ \\
Triglycerides $\left(\mathrm{mmol} \cdot \mathrm{l}^{-1}\right)$ & $0.47 \pm 0.13$ & $0.68 \pm 0.23$ & $0.54 \pm 0.20$ \\
\hline
\end{tabular}

$\mathrm{C}$ - control group; A - experimental group supplemented with $0.2 \%$ agrimony extract to water; AS - experimental group supplemented with a combination of $0.1 \%$ agrimony extract and $0.1 \%$ sage extract to water; SH groups - sulphydryl groups; GPx - gluthatione peroxidase; $\mathrm{Hb}$ - haemoglobin; SOD - superoxide dismutase; MDA - malondialdehyde; Results are presented as mean $\pm \mathrm{SD}$; ${ }^{\mathrm{a}, \mathrm{b}}$ - values in a row sharing different letters are statistically different $(P<0.05)$ 
Table 3. The effect of administration of plant extracts on chemical composition of meat and decomposition changes in fat, expressed as the amount of malondialdehyde $\left(\mathrm{mg}^{\mathrm{kg}} \mathrm{kg}^{-1}\right)$ during cold storage $\left(4^{\circ} \mathrm{C}\right)$ of thigh muscle.

\begin{tabular}{lcccc}
\hline Indicator & & $\mathrm{C}$ & $\mathrm{A}$ & $\mathrm{AS}$ \\
\hline Dry matter (\%) & Breast & $25.71 \pm 0.26^{\mathrm{b}}$ & $27.55 \pm 0.35^{\mathrm{a}}$ & $25.82 \pm 0.21^{\mathrm{b}}$ \\
& Thigh & $24.12 \pm 0.17$ & $24.64 \pm 0.45$ & $24.51 \pm 0.28$ \\
Fat (\%) & Breast & $2.01 \pm 0.58^{\mathrm{b}}$ & $2.89 \pm 0.12^{\mathrm{a}}$ & $1.99 \pm 0.10^{\mathrm{b}}$ \\
& Thigh & $5.90 \pm 0.33$ & $5.94 \pm 0.43$ & $5.60 \pm 0.85$ \\
Crude protein (\%) & Breast & $22.10 \pm 0.10$ & $22.10 \pm 0.20$ & $22.17 \pm 0.19$ \\
& Thigh & $17.77 \pm 0.19$ & $18.01 \pm 0.12$ & $18.21 \pm 0.29$ \\
TBARS (mg $\left.\cdot \mathrm{kg}^{-1}\right)$ & 1. day & $0.122 \pm 0.017^{\mathrm{a}}$ & $0.081 \pm 0.006^{\mathrm{b}}$ & $0.078 \pm 0.009^{\mathrm{b}}$ \\
& 8. day & $0.380 \pm 0.021^{\mathrm{a}}$ & $0.242 \pm 0.009^{\mathrm{c}}$ & $0.340 \pm 0.014^{\mathrm{b}}$ \\
\hline
\end{tabular}

$\mathrm{C}$ - control group; A - experimental group supplemented with $0.2 \%$ agrimony extract to water; $\mathrm{AS}$ - experimental group supplemented with a combination of $0.1 \%$ agrimony extract and $0.1 \%$ sage extract to water

TBARS - thiobarbituric acid reactive substances; Results are presented as mean $\pm \mathrm{SD} ; \mathrm{a}, \mathrm{b}, \mathrm{c}$ - values in a row sharing different letters are significantly different $(P<0.05)$

The effects of administration of $0.2 \%$ agrimony extract and a combination of $0.1 \%$ agrimony extract and $0.1 \%$ sage extract to water on the nutritional composition and oxidative stability of broiler meat is shown in Table 3. Only in group A, higher dry matter and fat content were found in the breast muscle. Protein content did not show any alterations in breast and thigh muscles due to the administration of the extracts in both experimental groups compared to the control group. The oxidative stability of meat was affected beneficially both in group A and AS because the TBARS concentration in thigh muscle was found to be decreased $(P<0.05)$ in both these groups compared to group $\mathrm{C}$.

\section{Discussion}

Inclusion of plant extracts in poultry nutrition is expected to improve the health status of the animals. Recent in vivo studies conducted in poultry (Faix et al. 2009; Kirkpinar et al. 2011; Ryzner et al. 2013) revealed beneficial effects of dietary supplementation of some herb extracts, especially essential oils, on blood biochemistry and antioxidant status of broilers. It is well known that plants and their extracts are a suitable source of herbal substances with antioxidant activities (Marcinčák et al. 2011). According to several authors, a combination of different plant extracts at appropriate concentrations can have more impact on the growth performance and health status of poultry than individual extracts due to synergistic interactions between herbal substances from various sources (Hong et al. 2012; Petrovic et al. 2012). The results obtained in our experiment did not confirm the existence of this phenomenon between the agrimony extract and sage extract at the concentrations administered in water. We can only speculate that administration of some herbal substances with antioxidant activities could lead to an enhanced antioxidant pool in the body, but direct mechanisms of their action are not well understood so far.

It is hypothesized that plant extracts supplemented to diet do not only affect the antioxidant status and biochemical indices in the blood of poultry, but via the improvement of some physiological processes, the sensory and physico-chemical properties of poultry meat can be beneficially influenced, too. In our experiment, higher dry matter content probably due to the higher fat content was observed only in the breast muscle of broilers supplemented with agrimony extract alone. Similarly, Nasir and Grashorn (2010) observed increased dry matter content in the breast muscle after the supplementation of Nigella sativa and 
Echinacea purpurea extracts, respectively, but in both these cases due to a higher content of crude protein. Moreover, some herbal extracts possess the ability to interfere with the cholesterol biosynthesis as its inhibitor, as mentioned later, but simultaneously they may be responsible for the activation of lipogenesis. For example, dietary supplementation of lemon balm caused an increase of PUFAs content in breast muscle according to the fatty acid analysis in broiler meat (Marcinčáková et al. 2011). In this experiment, supplementation of $0.2 \%$ agrimony extract alone as well as the combination of $0.1 \%$ agrimony extract with $0.1 \%$ sage extract to water have a beneficial effect on the degradation processes in thigh meat during storage at $4{ }^{\circ} \mathrm{C}$ for 8 days. Smet et al. (2008) also noted that rosemary, green tea and grape seed extracts had some antioxidant potential to limit the fat decomposition in refrigerated poultry muscles.

Plant extracts added to feed may influence cholesterol production in the blood and tissues via reduction of activities of enzymes involved in its metabolism. Some studies have indicated that pulverised herbal extracts (such as turmeric, oregano, anise, cinnamon, garlic, citrus peel) could reduce the level of cholesterol in poultry (Toghyani et al. 2011; Hong et al. 2012). Plant extracts may affect cholesterol levels by action on the enzyme acylCoA-cholesterol acyltransferase (ACAT), which esterifies cholesterol to its esters in tissues (Ciftci et al. 2010). The effect of agrimony on the reduction of total cholesterol is probably the same as in other plants, the inhibition of a 3-hydroxy-3-methylglutaryl coenzyme A reductase activity. Further research is required to clarify the hypocholesterolaemic and hypolipidaemic effects of the $0.2 \%$ agrimony extract found in our study.

In conclusion, the presented results indicate that only the supplementation of $0.2 \%$ agrimony extract in water can beneficially influence the antioxidant and lipid status in blood, as well as the nutritional composition of broiler meat and its oxidative stability after storage at $4{ }^{\circ} \mathrm{C}$ for 8 days. The addition of $0.1 \%$ agrimony extract with $0.1 \%$ sage extract to water has some antioxidant effects in blood and a beneficial effect on meat deterioration.

\section{Acknowledgment}

This study was supported by the Ministry of Education of the Slovak Republic (projects VEGA No. 1/0648/11 and $1 / 0457 / 14)$.

\section{References}

Arthur JR, Boyne R 1985: Superoxide dismutase and glutathione peroxidase activities in neutrophils from selenium deficient and cooper deficient cattle. Life Sci 36: 1569-1575

Ciftci M, Simsek UG, Yuce Y, Yilmaz O, Dalkilic B 2010: Effects of dietary antibiotic and cinnamon oil supplementation on antioxidant enzyme activities, cholesterol levels and fatty acid compositions of serum and meat in broiler chickens. Acta Vet Brno 79: 33-40

Ellman GL 1958: Tissue sulphydryl groups. Arch Biochem Biophys 82: 70-77

Faix Š, Faixová Z, Plachá I, Koppel J 2009: Effect of Cinnamomum zeylanicum essential oil on antioxidative status in broiler chickens. Acta Vet Brno 78: 411-417

Gião MS, Pereira CI, Fonseca SC, Pintado ME, Malcata FX 2009: Effect of particle size upon the extent of extraction of antioxidant power from the plants Agrimonia eupatoria, Salvia sp. and Satureja montana. Food Chem 117: 412-416

Gräber T, Kluge H, Granica S, Horn G, Brandsch C, Stangl GI 2014: Studies on the health impact of Agrimonia procera in piglets. BMC Vet Res 10: 210

Hong JCH, Steiner T, Aufy A, Lien TF 2012: Effects of supplemental essential oil on growth performance, lipid metabolites and imunity, intestinal characteristics, microbiota and carcass traits in broilers. Livest Sci 144: 253-262

Jayasena DD, Jo Ch 2014: Potential application of essential oils as natural antioxidants in meat and meat products: A review. Food Rev Int 30: 71-90

Jo C, Ahn DU 1998: Fluorometric analysis of 2-thiobarbituric acid reactive substances in turkey. Poult Sci 77: 475-480

Kirkpinar F, Unlu HB, Ozdemir G 2011: Effects of oregano and garlic essential oils on performance, carcase, organ and blood characteristics and intestinal microflora of broilers. Livest Sci 137: 219-225 
Luna A, Labaque MC, Zygadlo JA, Marin RH 2010: Effects of thymol and carvacrol feed supplementation on lipid oxidation in broiler meat. Poult Sci 89: $366-370$

Marcinčák S, Popelka P, Zdolec N, Mártonová M, Šimková J, Marcinčáková D 2011: Effect of supplementation of phytogenic feed additives on performance parameters and meat quality of broiler chickens. Slov Vet Res 48: $27-34$

Marcinčák S, Sokol J, Turek P, Popelka P, Nagy J 2006: Determination of MDA in pork meat using solid phase extraction and HPLC. Chem Listy 100: 528-532

Marcinčáková D, Čertík M, Marcinčák S, Popelka P, Šimková J, Klempová T, Petrovič V, Tučková M 2011: Effect of dietary supplementation of Melissa officinalis and combination of Achillea millefolium and Crataegus oxyacantha on broiler growth performance, and lipid oxidation of chicken meat. It J Anim Sci 10: 165-170

Nasir Z, Grashorn MA 2010: Effect of Echinacea purpurea and Nigella sativa supplementation on broiler performance and meat quality. J Anim Feed Sci 19: 94-104

Paglia DE, Valentine WN 1967: Studies on quantitative and qualitative characterization of erythrocyte glutathione peroxidase. J Lab Clin Med 70: 158-169

Petrovic V, Marcincak P, Popelka P, Simkova J, Martonova M, Buleca J, Marcincakova D, Tuckova M, Molnar L, Kovac G 2012: The effect of supplementation of clove and agrimony or clove and lemon balm on growth performance, antioxidant status and selected indices of lipid profile of broiler chickens. J Anim Physiol Anim Nutr 96: 970-977

Smet K, Raes K, Huyghebaert G, Haak L, Arnouts S, De Smet S 2008: Lipid and protein oxidation of broiler meat as influenced by dietary natural antioxidant supplementation. Poult Sci 87: 1682-1688

Ryzner M, Takáčová J, Cobanová K, Plachá I, Venglovská K, Faix Š 2013: Effect of dietary Salvia officinalis essential oil and sodium selenite supplementation on antioxidative status and blood phagocytic activity in broiler chickens. Acta Vet Brno 82: 43-48

Toghyani M, Toghyani M, Ghalamkari G, Eghbalsaied A 2011: Evaluation of cinnamon and garlic acid as antibiotic growth promoter substitutions on performance, serum biochemical and haematological parameters in broiler chicks. Livest Sci 138: 167-173

Vašková J, Veliká B, Pilatová M, Kron I, Vaško L 2011: Effects of humic acids in vitro. In Vitro Cell Dev BiolAnim 47: 376-382

Windisch W, Schedle K, Plitzner K, Kroismayr A 2008: Use of phytogenic products as feed additives for swine and poultry. J Anim Sci 86: 140-148 